\title{
A Case-Control Study on Maternal caffeine intake during Pregnancy and Risk of Low Birth Weight in Wolaita zone, Southern Ethiopia
}

Leila Hussen ( $\square$ leilahussen66@gmail.com )

Wolaita Sodo University

Blen Desu

Wolaita Sodo University

Research Article

Keywords: caffeine, coffee, birth weight, pregnancy, case-control.

Posted Date: December 4th, 2020

DOI: https://doi.org/10.21203/rs.3.rs-113435/v1

License: @ (i) This work is licensed under a Creative Commons Attribution 4.0 International License. Read Full License 


\section{Abstract}

Background: World Health Organization (WHO) recommends caffeine intake during pregnancy should be lower than $300 \mathrm{mg} /$ day. Maternal caffeine intake is associated with adverse birth outcomes. However, little information is available on maternal caffeine consumption during pregnancy and its effect on birth weight.

Objective: This study aimed to evaluate the level of maternal caffeine intake during pregnancy and its effect on birth weight in Wolaita zone hospitals in South Ethiopia. .

Method: The case-control study design was applied from March 1 to July 30, 2019. A total of 395 mothers (99cases and 296 controls) were interviewed by trained data collectors using a structured and pretested questionnaire. Anthropometric measurements were taken both from mothers and newborns. The association between maternal caffeine intake and birth weight was computed through bivariable and multivariable logistic regression analyses and statistical significance was declared at $p$-value $<$ 0.05 .

Results: Mean $( \pm S D)$ caffeine intake among pregnant women was $342 \pm 172 \mathrm{mg} /$ day. A vast majority of the respondents $374(94.7 \%)$ consumed caffeine during the current pregnancy, out of this $269(68 \%)$ ingested $300 \mathrm{mg}$ or more of caffeine per day (high consumers).

Relatively more mothers of low birth weight infants were consumed high caffeine $87(87.9 \%)$ compared with controls (51.5\%). multivariable logistic regression model indicated that those mothers who consumed high caffeine during pregnancy were four times more likely to have a newborn with low birth weight (AOR= 4.1 ( $95 \%$ $\mathrm{Cl} 1.2,10.1)$

Conclusion: This research result gives insight for health professional should be aware of the impact of heavy caffeine consumption on birth outcome and try to screen and consulate pregnant mothers who are at risk of having infants with LBW and provide skilled nutritional counseling during ANC visits, including the intake of caffeine.

\section{Introduction}

Weight at birth is a good pointer of maternal and fetal healthiness and nourishment[1]. Low birth weight infants have more risk of dying in the first month of life. Those who survive are more probable to experience inhibited growth, adulthood stunting that, in turn leading to the intergenerational effect of undernourishment, lower cognitive development, and chronic non-communicable diseases later in life. In addition to its direct consequences on physical and mental health, LBW has significant socioeconomic bearings, such as low workplace efficiency and increased costs on healthcare, with adverse impacts on national development [2-4].

Birth weight can be determined by Many factors, might be related to fetal, maternal, or the physical environment. There is a growing evidence that maternal diet influences fetal growth and can increase the risk for pregnancy complications. Maternal excessive caffeine intake during pregnancy has also been suggested as a risk factor for low birth weight [1-7]. 
Caffeine (1, 3, 7- trimethyl xanthine), is a plant alkaloid found mainly in coffee, tea, cola soft drinks, and cocoa/chocolate and available worldwide is thus frequently consumed during pregnancy. In pregnant ladies, clearance of caffeine from the body is delayed, in particular in the second and third trimesters, because of reduced activity of the liver enzyme that is responsible for caffeine metabolism [7-8]. Caffeine can also pass through all biological membranes and freely crosses the blood-brain barrier, and the placenta in pregnant women. Maternal and fetal plasma can attain equilibrium [9]. The immature fetal liver enzyme is not capable to metabolize it, ensuing in the accumulation of caffeine in the fetus this can increase the concentration of cellular cyclic adenosine mono phosphate (cAMP), interfering in fetal cell growth and development.

furthermore, caffeine cause mainly its biological outcomes through inhibiting all kinds of adenosine receptors and increasing the catecholamine concentrations within the mother among the fetus, leading to reduced placental blood flow and hinders placental nutrient and oxygen transport to the fetus[9-10].

World Health Organization (WHO) guidelines recommend a caffeine intake should be lower than $300 \mathrm{mg} / \mathrm{day}$ during pregnancy. However, current recommendations of the European Food Safety Authority (EFSA) and the American Institute of Medicine have restricted the amount to $200 \mathrm{mg} /$ day [11-13].

Studies showed that high maternal caffeine intake during pregnancy may lead to a miscarriage, preterm delivery, or low-birth weight. Many studies have shown an increased risk of low -birth weight when daily maternal caffeine intake above 300 mg, a daily caffeine consumption between 151 and 300 mg, and infrequently even 150 mg or lower has been associated with risks of low birth weight[14,15,17,18,19].

Coffee plays a significant role in each cultural and social life of the Ethiopian society besides the most popular beverage in the country and the most common source of caffeine during pregnancy [20]. Despite the significant effect of caffeine consumption with adverse birth outcomes, however, little information is available on maternal coffee consumption during pregnancy in Ethiopia. Thus, this study aimed to evaluate the level of maternal coffee intake during pregnancy and its effect on birth weight in hospitals in the Wolaita zone.

\section{Methods And Materials}

\section{Study area, design, and period}

The Wolaita zone is one of the fourteen zones of the Southern Nation Nationalities and Peoples Region (SNNPR), which is $327 \mathrm{~km}$ from Addis Ababa, the capital of Ethiopia. The zone has a total area of 4512 square kilometers, administratively divided into 12 districts and 3 town administrations with a total population of nearly 1.7 million. According to the zonal health office report, 8 hospitals( out of this 1 is a referral hospital, 5 primaries governmental and 2 nongovernmental). 342 health posts, 10 private clinics, and 67 health centers are in the zone. A facility- based case control study design was conducted in three hospitals in Wolaita zone: Wolaita Sodo referral hospital, Dubo and Bonbe primary hospital from March 1 to July 30, 2019. In 2018, the total number of births from the three hospitals was 6,189.

\section{Study population}

All mothers who gave birth in the three hospitals were the source population. Mothers who gave live births weighing less than $2500 \mathrm{~g}$ were considered as cases and live births weighed $2500 \mathrm{~g}$ and above as controls. 
Term newborns and Singletons were included. Birth outcomes such as congenital malformations, mothers who had diabetes mellitus, hypertension, and an unknown last normal menstrual period were excluded.

\section{Sample size determination and sampling techniques}

The sample size was calculated using the proportion difference approach with the following assumptions: level of confidence $95 \%(Z \alpha / 2=1.96)$, power $80 \%(Z \beta=0.84)$, and the ratio of control to case 3to1 the odds ratio to be detected greater than 2 and 20\% [21] of the control group to be exposed, With the anticipation of $10 \%$ nonresponse rate, the final sample size was 403 , which is 101 cases and 302 controls. It was proportionally assigned based on the number of prior childbirth attendance. The weight of all live births delivered in the selected hospitals of the Wolaita zone during the study period was measured. According to the case definition, those mothers who gave live births weighed less than $2500 \mathrm{~g}$ included in the study as cases. For each case, three consecutive controls were included.

\section{Data collection tools and procedure}

Data were collected with structured and pretested questionnaires through face- to -face interviews. The tools were adapted from Caffeine Consumption Questionnaire-Revised (CCQ-R) and the Ethiopian Demographic Health survey and other peer- reviewed articles(additionalfile1) [21-24]. It consists of the socio-demographic background, maternal /obstetric, and coffee consumption related questions. The questionnaire was initially prepared in English and then translated to local language and back- translated to English to observe its consistency. A pre-test was done with 20 respondents who were later not included in the main study. In addition, training was given to data collectors on the different components of the questionnaire, study participants selection, anthropometric measurements, and ethics.

Anthropometric measures were standardized for technical Errors against an expert measurer and always checked and zeroed before weighing each newborn. Weights of newborns were measured within an hour after birth with a digital weight scale. Maternal weight was measured using a digital weight measuring scale to the nearest gram.

Caffeine intake from coffee is the main sources of caffeine in the diet of pregnant women according to the available literature in Ethiopia [20]. Habitual Dietary caffeine intake from coffee was assessed by habitual daily coffee consumption. The amount of coffee consumption was measured by using a cup of coffee per day. Participants were asked about the frequency and type of cups they consumed in the last 24-hr. The Photo Album was used to precisely evaluate portion size. The daily 24-hr recall consumption data were converted in to milliliters $(\mathrm{ml})$, after that data was multiplied by the amount of caffeine from coffee in each milliliter $(0.5309$ $\mathrm{mg} / \mathrm{ml}$ was obtained from a study conducted in Ethiopia)[20]. Finally, Caffeine consumption from coffee during pregnancy was categorized as none consumer, low consumer $(<300 \mathrm{mg} /$ day $)$, and high consumer $(\geq 300$ $\mathrm{mg} /$ day), according to the Care Study Group [25].

\section{Data processing and analysis}

Data were entered into Epi-Info (Version 6.0), cleaned, and exported to IBM SPSS for Windows (Version 20.0) for analysis. Descriptive statistics such as means and standard deviations, frequency, percentages, and crosstabulations were computed for the case and control groups. Bivariable binary logistic regression was applied to 
see the crude effect of each independent variable on the dependent variable (birth weight). Variables with Pvalues $<0.25$ were taken for multivariable logistic regression analysis. Finally, a multivariate logistic regression analysis was done to control for potential confounders and identify independent predictors of low birth weight. Consequently, we reported AORs with $95 \% \mathrm{Cls}$, and statistical significance declared at p-value $<0.05$.

\section{Results}

From a total of 403 sample sizes, 395 mothers (99 cases and 296 controls) were involved in the study, with a response rate of $98 \%$. The mean age $( \pm S D)$ of respondents was $26.5( \pm 5.1)$ which ranged to $16-39$ years. About three - fourth $78(78.8 \%)$ of cases and $83.1 \%$ of controls were aged $20-34$ years. The majority $(83.8 \%)$ of cases and about half of the controls were rural residents. $65.7 \%$ of cases and about $27.4 \%$ of controls had no formal education.

Concerning monthly family income; a third of the cases and $11 \%$ of the controls had an income of less than 800 ETB (26\$). More than two -thirds, $43(69.4 \%)$ of mothers in the cases and $26.9 \%$ of the controls gave birth to the current newborn within two years ( $\leq 24$ months) after previous childbirth. Sixty-six mothers $(89.6 \%)$ in the cases weighed below $50 \mathrm{~kg}$ during their pregnancy and about two-thirds, $66(66.7 \%)$ of cases stayed with prepregnancy weight (see Table 1).

Table 1 Distribution of mothers by socio-demographic characteristics in hospitals at Wolaita zone in South Ethiopia, July 2019(n=395) 


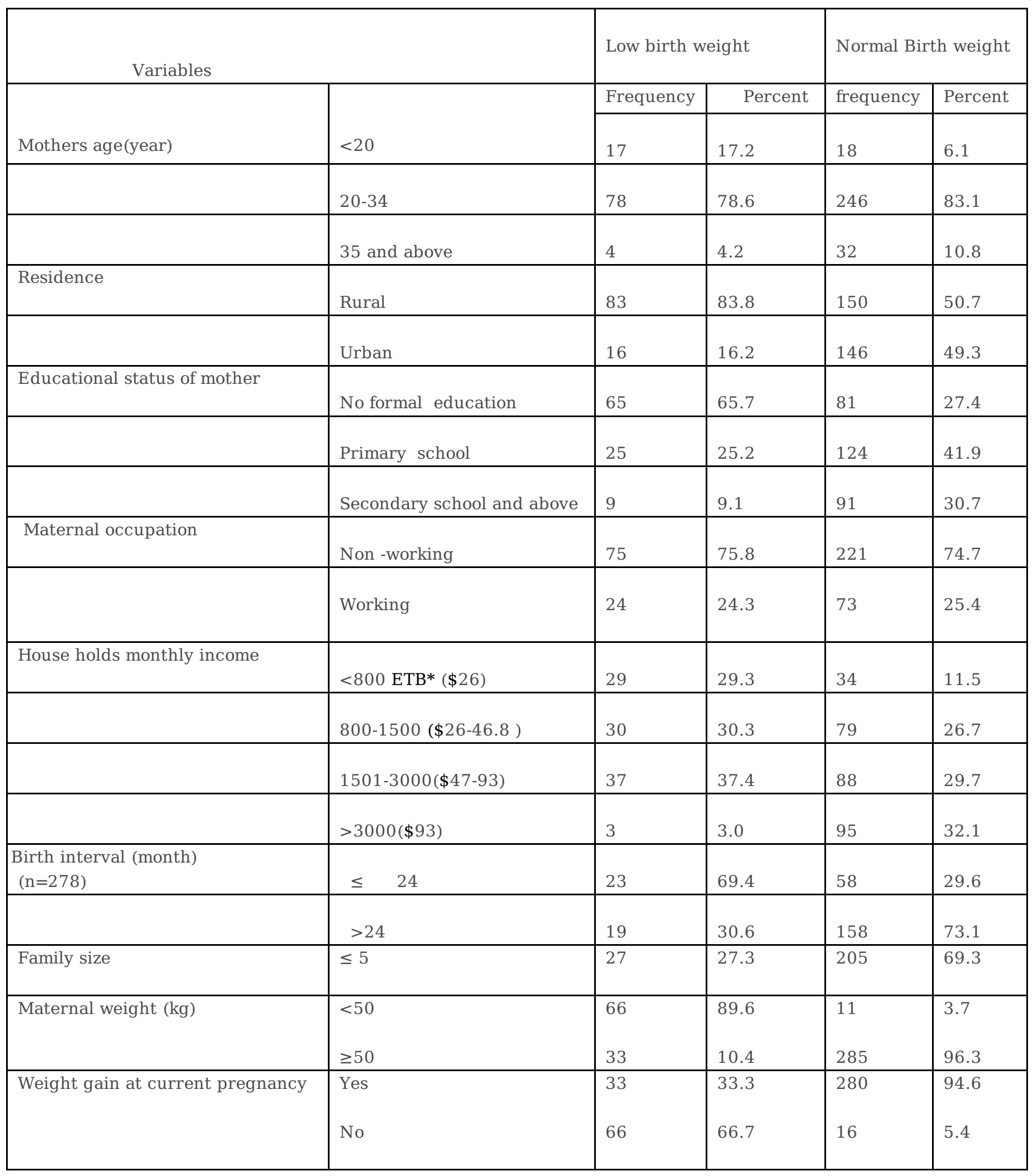

Abbreviations; ETB* Ethiopian birr

Mean ( $\pm S D$ ) caffeine intake among pregnant women was $342 \pm 172 \mathrm{mg} /$ day. A vast majority of the respondents $374(94.7 \%)$ consumed coffee during the current pregnancy, out of this $269(68 \%)$ ingested $300 \mathrm{mg}$ or more of caffeine per day (high consumers), while the remaining 105(26.6\%) and $21(5.3 \%)$ respondents were low consumer $(<300 \mathrm{mg} /$ day) and non-consumers respectively. 
The mean ( $\pm S D)$ caffeine intake among cases and controls was $433 \pm 177$ and $312 \pm 159 \mathrm{mg} /$ day respectively. Relatively more mothers of low birth weight infants were consuming high caffeine $87(87.9 \%)$ compared with controls (61.5\%). Three percent of the mothers of LBW infants were consumed less than $300 \mathrm{mg}$ caffeine per day, compared with $32.4 \%$ of mothers of the controls.

After controlling for other factors mothers with no formal education were more likely to ingest high caffeine than mothers with advanced educational status (AOR= 2.3; $95 \% \mathrm{Cl} 1,5.2)$.

On the other hand, non-working mothers were about two times more likely to ingest high caffeine $(A O R=2.2$; $95 \% \mathrm{Cl} 1.3,3.7)$.

Mothers residing in the rural areas were more likely to ingest high caffeine as compared to those from the nearby urban dwellers $(A O R=3.6(95 \% \mathrm{Cl} 2.1,6.2)$. Mothers who weighed less than $50 \mathrm{~kg}$ had about three times at a higher risk of consuming high caffeine than Mothers who weighed $50 \mathrm{~kg}$ and above(AOR $=3(95 \% \mathrm{Cl} 1.5$, 6.9)(Table 2).

Table 2, Factors associated with High Maternal caffeine intake during pregnancy in hospitals at Wolaita zone in South Ethiopia, July 2019(n=395) 


\begin{tabular}{|c|c|c|c|c|c|c|c|}
\hline \multirow[t]{3}{*}{ Variables } & & \multicolumn{2}{|c|}{$\begin{array}{l}\text { Coffee consumption } \\
\text { (mg/day) }\end{array}$} & \multirow{3}{*}{ COR $(95 \% \mathrm{CI})$} & \multirow{3}{*}{$\mathrm{P}$ value } & \multirow{3}{*}{$\operatorname{AOR}(95 \% \mathrm{CI})$} & \multirow{3}{*}{$\begin{array}{l}\mathrm{P} \\
\text { value }\end{array}$} \\
\hline & & \multicolumn{2}{|l|}{$\begin{array}{l}<300 \\
\geq 300\end{array}$} & & & & \\
\hline & & $\mathrm{N}(\%)$ & $\mathrm{N}(\%)$ & & & & \\
\hline \multirow[t]{3}{*}{$\begin{array}{l}\text { Mothers } \\
\text { age (year) }\end{array}$} & $<20$ & $11(34.4)$ & $21(65.6)$ & $0.6(0.2,1.7)$ & 0.36 & & \\
\hline & $20-34$ & $106(32.5)$ & $220(67.5)$ & $0.66(0.3,1.4)$ & 0.31 & & \\
\hline & $\begin{array}{l}35 \text { and } \\
\text { above }\end{array}$ & $9(24.3)$ & $28(75.7)$ & 1 & & & \\
\hline \multirow[t]{2}{*}{ Residence } & Rural & \begin{tabular}{|l}
$46(19.6)$ \\
\end{tabular} & 189(80.4) & $4.1(2.6,6.4)$ & $<0.0001$ & $3.6(2.1,6.2)$ & 0.0001 \\
\hline & Urban & $80(50)$ & $80(50)$ & 1 & & & \\
\hline \multirow{3}{*}{$\begin{array}{l}\text { Educational } \\
\text { status of } \\
\text { mother }\end{array}$} & $\begin{array}{l}\text { No formal } \\
\text { education }\end{array}$ & $24(16.4)$ & $122(83.6)$ & $5.5(3,9.9)$ & $<0.0001$ & $2.3(1.0,5.2)$ & 0.03 \\
\hline & $\begin{array}{l}\text { Primary } \\
\text { school }\end{array}$ & $51(33.8)$ & $100(66.2)$ & $2.1(1.2,3.5)$ & 0.004 & $1.3(0.7,2.4)$ & 0.34 \\
\hline & $\begin{array}{l}\text { Secondary } \\
\text { and above }\end{array}$ & $51(52)$ & $47(48)$ & 1 & & 1 & \\
\hline \multirow[t]{2}{*}{$\begin{array}{l}\text { Maternal } \\
\text { Jccupation }\end{array}$} & $\begin{array}{l}\text { Non - } \\
\text { working }\end{array}$ & $87(28)$ & $224(72)$ & $2.2(1.3,3.6)$ & 0.001 & $2.2(1.3,3.7)$ & 0.002 \\
\hline & Working & \begin{tabular}{|l}
$39(46.4)$ \\
\end{tabular} & $45(53.6)$ & 1 & & & \\
\hline \multirow{4}{*}{$\begin{array}{l}\text { House } \\
\text { holds } \\
\text { monthly } \\
\text { income }\end{array}$} & $\begin{array}{l}<800 \text { ETB* } \\
(\$ 26)\end{array}$ & 13(19.7) & $53(80.3)$ & 1 & & & \\
\hline & $\begin{array}{l}800-1500 \\
(\$ 26-46.8)\end{array}$ & $29(27.6)$ & $76(72.4)$ & $0.6(0.3-1.3)$ & 0.23 & \begin{tabular}{|l|}
$0.75(0.35,1.6)$ \\
\end{tabular} & 0.4 \\
\hline & $\begin{array}{l}1501- \\
3000(\$ 47- \\
93)\end{array}$ & \begin{tabular}{|l}
$26(26.3)$ \\
\end{tabular} & 73(73.7) & $0.68(0.3-1.4)$ & 0.332 & \begin{tabular}{|l|}
$0.98(0.44,2.1)$ \\
\end{tabular} & 0.9 \\
\hline & $>3000(\$ 93)$ & $58(46.4)$ & 67(53.6) & $0.28(0.14-0.57)$ & 0.001 & $0.69(0.3,1.5)$ & 0.37 \\
\hline \multirow{2}{*}{$\begin{array}{l}\text { Maternal } \\
\text { weight }(\mathrm{kg})\end{array}$} & $<50$ & $9(11.7)$ & $68(88.3)$ & $4.3(2.1,9.1)$ & 0.001 & $3.2(1.5,6.9)$ & 0.02 \\
\hline & $\geq 50$ & $117(36.8)$ & $201(63.2)$ & 1 & & 1 & \\
\hline
\end{tabular}

Abbreviations; COR crude odds ratio, AOR adjusted odds ratio ,ETB Ethiopian birr,

Notes; *Significant at p-value $<0.05, * *$ Significant at $\mathrm{p}$-value $<0.01$ and $* * *$ Significant at p-value $<0.001$

The relationship between exposure to caffeine intake and LBW was evaluated after adjusting for residence, maternal education, maternal occupational status, family monthly income, maternal body weight, antenatal care, and birth interval.

Therefore, the multivariable logistic regression model indicated that those mothers who consumed high caffeine during pregnancy were four times more likely to have a newborn with low birth weight (AOR= 4.1 ( $95 \%$ Cl 1.2, 10.1)(table3). 
Table 3, Bivariate and multivariate logistic regression analysis of factors associated LBW among term newborn in Wolaita zone hospitals, south Ethiopia, July 2019(n=395)

\begin{tabular}{|c|c|c|c|c|c|}
\hline \multirow[t]{2}{*}{$\overline{\text { Irs }}$} & & \multicolumn{2}{|c|}{$\begin{array}{c}\text { Birth } \\
\text { weight N }(\%)\end{array}$} & \multirow[t]{2}{*}{ COR(95\%CI) } & \multirow[t]{2}{*}{ AOR(95\%CI) } \\
\hline & & $\begin{array}{l}\text { Low N } \\
(\%)\end{array}$ & $\begin{array}{l}\text { Normal N } \\
(\%)\end{array}$ & & \\
\hline \multirow[t]{2}{*}{$\begin{array}{l}\text { rnal } \\
\text { ation }\end{array}$} & No formal education & $65(65.7)$ & $81(27.4)$ & \begin{tabular}{|l|}
$7.9(3.7-$ \\
$16.9)$
\end{tabular} & NS \\
\hline & $\begin{array}{l}\text { Primary school } \\
\text { Secondary and above }\end{array}$ & $\begin{array}{l}25(25.2) \\
9(9.1)\end{array}$ & $\begin{array}{l}\text { 124(41.9) } \\
91(30.9)\end{array}$ & $\begin{array}{l}1.9(0.8-4.4 \\
1\end{array}$ & \\
\hline \multirow{5}{*}{$\begin{array}{l}\text { rnal } \\
\text { sational } \\
\text { s } \\
\text { ly monthly } \\
\text { ne }\end{array}$} & $\begin{array}{l}\text { Non -working } \\
\text { Working }\end{array}$ & $\begin{array}{l}75(75.8) \\
24(24.3)\end{array}$ & $\begin{array}{l}221(74.7) \\
73(25.2)\end{array}$ & \begin{tabular}{|l|}
$4.9(2.7-8.7)$ \\
1
\end{tabular} & NS \\
\hline & $<800$ ETB* $^{*}(\$ 26)$ & $29(29.3)$ & $34(11.5)$ & $3.6(2.5-7.8)$ & $2.5(0.9-8.6)$ \\
\hline & $800-1500(\$ 26-46.8)$ & $30(30.3)$ & $79(26.7)$ & $3.4(1.6-7.5)$ & $\begin{array}{l}2.2(0.68- \\
7.1)\end{array}$ \\
\hline & $1501-3000(\$ 47-93)$ & $37(37.4)$ & $88(29.7)$ & $3.3(1.5-7.2)$ & $\begin{array}{l}1.2(0.62- \\
5.9)\end{array}$ \\
\hline & $>3000(\$ 93)$ & $3(3.0)$ & $95(32.1)$ & 1 & \\
\hline \multirow[t]{2}{*}{ interval } & $<2$ years & $43(69.4)$ & $58(26.9)$ & $1.5(1.3-3.5)$ & $1.06(0.85-$ \\
\hline & $\geq 2$ years & $19(30.6)$ & $158(73.1)$ & 1 & \\
\hline \multirow{2}{*}{$\begin{array}{l}\text { e } \\
\text { amption(mg) }\end{array}$} & $<=300$ & $12(12.1)$ & $110(37.2)$ & 1 & 1 \\
\hline & $>300$ & $87(87.9)$ & $186(62.8)$ & $4.2(2.2-8.1)$ & $\begin{array}{l}4.1(1.2- \\
10.1)^{* * *}\end{array}$ \\
\hline \multirow[t]{2}{*}{ rnal weight } & $\leq 50$ & $66(89.6)$ & $11(3.7)$ & $8.3(5.8-16.4)$ & $7.2(4.4-$ \\
\hline & $>50$ & $33(10.4)$ & $285(96.3)$ & 1 & \\
\hline
\end{tabular}

Abbreviations AOR adjusted odds ratio, COR crude odds ratio, ETB Ethiopian birr ,kg kilogram ,mg milligram, NS not significant Notes *Significant at $\mathrm{p}$-value $<0.05, * *$ Significant at $\mathrm{p}$-value $<0.01$ and $* * *$ Significant at $\mathrm{p}$-value $<0.001$

\section{Discussion}

The main objective of this study was to evaluate the level of maternal coffee intake during pregnancy and its effect on birth weight. In the present study most of our study participants drank coffee during current pregnancy. In our study, nearly three - fourth $(68 \%)$ of mothers were high caffeine consumers (had a daily caffeine consumption of more than or equal to $300 \mathrm{mg} /$ day). We observed a higher proportion of heavy caffeine consumption among the investigated population as compared to similar studies in southern Ethiopia (17\%) [20] and elsewhere (27.3\%) [16].The possible clarification could be our study setting, Wolaita area is one of coffee- producing area in the country. This study revealed that relatively more mothers of low birth weight 
infants were consumed high caffeine compared with controls. This result is supported by other similar studies in which more mothers of low birth weight babies consumed high caffeine than mothers with normal birth weight babies [16].

While some studies have found that high caffeine intake during pregnancy increases the risk of LBW $[6,7,9]$ other studies did not find a significant association $[10,19,26]$. This discrepancy might be due to differences in study populations, sample size, study design, and handling of potentially confounding variables. In our study, we found those mothers who consumed high caffeine, that of more than or equal to 300 mg daily, were four times more likely to have a newborn with low birth weight.

This result is supported by results from a hospital-based case-control study in northern California, which showed that, after adjusting for other known risk factors of low birth weight, heavy maternal caffeine consumption, that of $300 \mathrm{mg}$ or more daily, the risk of low birth weight by a factor of three [16]. It has also been demonstrated through meta-analyses and systematic review that higher maternal caffeine intake during pregnancy increases the risk for both low birth weight infants [27,28,29].

Some limitations that might have affected the findings of the present study should be noted. The first of these limitations is that; we collected data on maternal caffeine intake on the day of the delivery; this may result in recall biases. Nonetheless, drinking coffee is a common component of many individuals eating habits and it should not be difficult to recall the frequency of their consumption. Additionally, The questionnaires employed did not have information about other sources of caffeine, such as Tea and soft drinks, studies have previously reported that coffee is The major sources of caffeine also is the sources of over $90 \%$ of the caffeine in the diets of pregnant women in the study area. Also, caffeine intake might have been different throughout the pregnancy, although different studies showed that a lack of significant difference between caffeine intake and trimesters of pregnancy However, furthermore detail study verifying trimester of gestation and caffeine intake is recommended.

\section{Conclusions}

This study estimated the level of maternal coffee intake during pregnancy and its effect on birth weight. In this study, we found a high prevalence of maternal higher caffeine intake during pregnancy. The results of the present study indicate that higher maternal caffeine intake during pregnancy is associated with a higher risk of delivering low birth weight infants. Mothers with no formal education, non-working, residing in a rural area, and mothers who weighed less than $50 \mathrm{~kg}$ were more likely to consume higher caffeine.

Health service providers should be aware of the impact of heavy caffeine consumption on birth outcome and try to screen and consulate pregnant mothers who are at risk of having infants with LBW and provide skilled nutritional counseling during ANC visits, including the intake of caffeine.

\section{Abbreviations}

ANC: Antenatal care; AOR: Adjusted odds ratio ;Cl: Confidence interval; DHS: Demography and Health Survey;FMOH: Federal Ministry of Health; kg: kilogram; LBW: Low birth weight;NBW: Normal birth weight; OR: Odds ratio; USD: United States Dollar; WHO: World Health Organization. 


\section{Declarations}

\section{Ethics approval and consent to participate}

We obtained ethical clearance and support letter for the study from the ethical review committee at the College of Health Sciences and Medicine Wolaita Sodo University in Ethiopia. The support letter submitted to Wolaita Zone Health Bureau which is a higher government body responsible for health and health research. Then, the Wolaita Zone Health Bureau communicated with the respective selected hospital, Permission letters were secured from the Wolaita Zone Health Bureau and each hospital. This study was conducted in accordance with the Helsinki Declaration and after informing the purpose and procedures of the study, written informed consent was obtained from each mother prior to the interview. For participants who were under 18 written consent was obtained from the parents and assent from mothers before the data was collected. The data collectors explained to the study participants that they have the right to refuse an interview at any time if they were not happy to continue in addition, the benefit of participation in the study and confidentiality of the information collected

\section{Competing of interest}

The authors declare that they have no conflicts of interest in this work.

\section{Consent for publication}

Not applicable

\section{Availability of data}

The data sets used during the current study are available from the corresponding author on reasonable request.

\section{Funding}

Not applicable

\section{Author contributions}

LH; designed the protocol, coordinated data collection, made analysis and interpreted findings, and drafted the manuscript.

BKD; contributed in design, analysis, interpretation of the findings, and drafting the manuscript

All the authors read gave final approval of the version to be published, and agree to be accountable for all aspects of the work.

\section{Acknowledgments ;}

We would like to acknowledge Wolaita Soddo University Teaching and Referral Hospital, Dubo and Bonbe primary hospital for their cooperation. We want also to thank the study participants, data collectors and supervisors. 


\section{References}

[1].WHO. WHA Global Nutrition Targets 2025: Low Birth Weight Policy Brief. Nutrition: low birth weight. 2014.

[2].WHO G, World Health Organization. WHO guide line on optimal feeding of low birth weight in low and middle income countries. 2011.

[3].He Z, BG, Yaya S, et al . Prevalenceof low birth weight and itsassociation with maternalbody weight status in selectedcountries in Africa: a crosssectional study. BMJ Open. 2018.

[4].Sutan R. Determinants of low birth weight infants: a matched case control study. Open J Prev Med.; 4:91-9. 2014.

[5].United Nations Children's Fund and World Health Organization. Low Birthweight: Country,regional and global estimates. UNICEF, New York,. 2004.

[6].Chen, Ling-Wei, et al. "Associations of Maternal Caffeine Intake with Birth Outcomes: Results from the Lifeways Cross Generation Cohort Study." The American Journal of Clinical Nutrition, vol. 108, no. 6, Dec. 2018, pp. 1301-08. DOl.org (Crossref), doi:10.1093/ajcn/nqy219.

[7]. Sengpiel, V., Elind, E., Bacelis, J. et al. Maternal caffeine intake during pregnancy is associated with birth weight but not with gestational length: results from a large prospective observational cohort study. BMC Med 11, 42 (2013). https://doi.org/10.1186/1741-7015-11-42

[8]. Tsutsumi, K. "The Effect of Pregnancy on Cytochrome P4501A2, Xanthine Oxidase, and N Acetyl transferase Activities in Humans." Clinical Pharmacology \& Therapeutics, vol. 70, no. 2, Aug. 2001, pp. 121-25. DOI.org (Crossref), doi:10.1067/mcp.2001.116495.

[9]. James, Jack E. "Maternal Caffeine Consumption and Pregnancy Outcomes: A Narrative Review with Implications for Advice to Mothers and Mothers-to-Be." BMJ Evidence-Based Medicine, Aug. 2020, p. bmjebm2020-111432. DOI.org (Crossref), doi:10.1136/bmjebm-2020-111432.

[10]. Wierzejska, Regina, et al. "Caffeine Intake During Pregnancy and Neonatal Anthropometric Parameters." Nutrients, vol. 11, no. 4, Apr. 2019, p. 806. DOl.org (Crossref), doi:10.3390/nu11040806.

[11]. World Health Organization, editor. WHO Recommendations on Antenatal Care for a Positive Pregnancy Experience. World Health Organization, 2016.

[12]. EFSA Panel on Dietetic Products Nutrition and Allergies. Scientific opinion on the safety of caffeine. EFSA J.2015, 13, 4-102.

[13]. Institute of Medicine. Caff eine in Food and Dietary Supplements: Examining Safety, National Academies Press:Washington, DC, USA, 2014

[14]. Nawrot, P., et al. "Effects of Caffeine on Human Health." Food Additives and Contaminants, vol. 20, no. 1, Jan. 2003, pp. 1-30. DOI.org (Crossref), doi:10.1080/0265203021000007840. 
[15]. Vlajinac, H. D., et al. "Effect of Caffeine Intake During Pregnancy on Birth Weight." American Journal of Epidemiology, vol. 145, no. 4, Feb. 1997, pp. 335-38. DOl.org (Crossref), doi:10.1093/oxfordjournals.aje.a009110.

[16]. Caan, B. J., and M. K. Goldhaber. "Caffeinated Beverages and Low Birthweight: A Case-Control Study." American Journal of Public Health, vol. 79, no. 9, Sept. 1989, pp. 1299-300. DOl.org (Crossref), doi:10.2105/AJPH.79.9.1299.

[17]. Srisuphan, Wichit, and Michael B. Bracken. "Caffeine Consumption during Pregnancy and Association with Late Spontaneous Abortion." American Journal of Obstetrics and Gynecology, vol. 154, no. 1, Jan. 1986, pp. 14-20. DOI.org (Crossref), doi:10.1016/0002-9378(86)90385-6.

[18]. Pastore, Lisa M., and David A. Savitz. "Case-Control Study of Caffeinated Beverages and Preterm Delivery." American Journal of Epidemiology, vol. 141, no. 1, Jan. 1995, pp. 61-69. DOl.org (Crossref), doi:10.1093/oxfordjournals.aje.a117346.

[19].Santos, I. S., et al. "Caffeine Intake and Low Birth Weight: A Population-Based Case-Control Study." American Journal of Epidemiology, vol. 147, no. 7, Apr. 1998, pp. 620-27. DOI.org (Crossref), doi:10.1093/oxfordjournals.aje.a009502.

[20]. Alamneh, Alehegn Aderaw, et al. "Caffeine, Alcohol, Khat, and Tobacco Use during Pregnancy in Butajira, South Central Ethiopia.” PLOS ONE, vol. 15, no. 5, May 2020, p. e0232712. DOl.org (Crossref), doi:10.1371/journal.pone.0232712.

[21]. Habtamu D, Achenif M, Dabere N,et al. Risk factors for low birth weight in Bale Zone Hospital, South East Ethiopia, a case control study. BMC Pregnancy and Childbirth. 2015 15:264.

[22]. [Ethiopia] CSACalIFrAA, Rockville: Central Statistical Authority; 2017. Ethiopia demographic and health survey 2016

[23]. CSA. Ethiopia demographic and health survey. 2011

[24]. Irons JG, Bassett DT, Prendergast CO, Landrum RE, Heinz AJ. Development and Initial Validation ofthe Caffeine Consumption Questionnaire-Revised. Journal of Caffeine Research. 2016; 6(1):20-5.

[25]. CARE Study Group. Maternal caffeine intake during pregnancy and risk of fetal growth restriction: a large prospective observational study. BMJ 2008;337:a2332 Doi10.1136/bmj.a2332

[26]. Vitti, Fernanda, et al. "Association between Caffeine Consumption in Pregnancy and Low Birth Weight and Preterm Birth in the Birth Cohort of Ribeirão Preto." Revista Brasileira de Ginecologia e Obstetrícia / RBGO Gynecology and Obstetrics, vol. 40, no. 12, Dec. 2018, pp. 749-56. DOl.org (Crossref), doi:10.1055/s-00381675806.

[27]. Fortier, Isabel, et al. "Relation of Caffeine Intake during Pregnancy to Intrauterine Growth Retardation and Preterm Birth." American Journal of Epidemiology, vol. 137, no. 9, May 1993, pp. 931-40. DOl.org (Crossref), doi:10.1093/oxfordjournals.aje.a116763. 
[28]. Rhee, Jongeun, et al. "Maternal Caffeine Consumption during Pregnancy and Risk of Low Birth Weight: A Dose-Response Meta-Analysis of Observational Studies." PLOS ONE, edited by Baohong Zhang, vol. 10, no. 7, July 2015, p. e0132334. DOl.org (Crossref), doi:10.1371/journal.pone.0132334.

[29]. Chen, Ling-Wei, et al. "Maternal Caffeine Intake during Pregnancy Is Associated with Risk of Low Birth Weight: A Systematic Review and Dose-Response Meta-Analysis." BMC Medicine, vol. 12, no. 1, Dec. 2014, p. 174. DOI.org (Crossref), doi:10.1186/s12916-014-0174-6.

\section{Supplementary Files}

This is a list of supplementary files associated with this preprint. Click to download.

- supplementalfile.docx 